\title{
Temporal trends in non-occupational sedentary behaviours from Australian Time Use Surveys 1992, 1997 and 2006
}

\author{
Josephine Y Chau ${ }^{1 *}$, Dafna Merom ${ }^{1,2}$, Anne Grunseit ${ }^{1}$, Chris Rissel ${ }^{1}$, Adrian E Bauman ${ }^{1}$ and Hidde P van der Ploeg ${ }^{1}$
}

\begin{abstract}
Background: Current epidemiological data highlight the potential detrimental associations between sedentary behaviours and health outcomes, yet little is known about temporal trends in adult sedentary time. This study used time use data to examine population trends in sedentary behaviours in non-occupational domains and more specifically during leisure time.

Methods: We conducted secondary analysis of population representative data from the Australian Time Use Surveys 1992, 1997 and 2006 involving respondents aged 20 years and over with completed time use diaries for two days. Weighted samples for each survey year were: $n=5851$ (1992), $n=6419$ (1997) and $n=5505$ (2006). We recoded all primary activities by domain (sleep, occupational, transport, leisure, household, education) and intensity (sedentary, light, moderate). Adjusted multiple linear regressions tested for differences in time spent in nonoccupational sedentary behaviours in 1992 and 1997 with 2006 as the reference year.

Results: Total non-occupational sedentary time was slightly lower in 1997 than in 2006 (mean = $894 \mathrm{~min} / 2 \mathrm{~d}$ and $906 \mathrm{~min} / 2 \mathrm{~d}$, respectively; $B=-11.2 ; 95 \% \mathrm{Cl}:-21.5,-0.9)$. Compared with 2006, less time was spent in 1997 in sedentary transport (B-6.7; 95\%Cl: $-10.4,-3.0)$ and sedentary education ( $\mathrm{B}=-6.3 ; 95 \% \mathrm{Cl}$ : $-10.5,-2.2)$ while household and leisure sedentary time remained stable. Time engaged in different types of leisure-time sedentary activities changed between 1997 and 2006: leisure-time computer use increased ( $\mathrm{B}=-26.7$; 95\%Cl: -29.5, -23.8), while other leisure-time sedentary behaviours (e.g., reading, listening to music, hobbies and crafts) showed small concurrent reductions. In 1992, leisure screen time was lower than in 2006: TV-viewing ( $B=-24.2 ; 95 \% \mathrm{Cl}:-31.2,-17.2)$, computer use ( $B=-35.3 ; 95 \% \mathrm{Cl}:-37.7,-32.8)$. In 2006, $90 \%$ of leisure time was spent sedentary, of which $53 \%$ was screen time.
\end{abstract}

Conclusions: Non-occupational sedentary time has increased slightly from 1997 to 2006 in the Australian adult population. This seems to be the result of small increases in sedentary transport and education time while sedentary household and leisure time were stable over this time period. However, almost all leisure time is spent sedentary and the composition of sedentary leisure time changed between 1992 and 2006 towards a larger proportion being screen-based activities. This could be an important observation for public health, as most of the evidence on the detrimental effects of sedentary behaviour is around watching television and health.

\footnotetext{
* Correspondence: josephine.chau@sydney.edu.au

'Prevention Research Collaboration, Sydney School of Public Health, University of Sydney, Sydney, Australia

Full list of author information is available at the end of the article
} 


\section{Background}

Sedentary behaviours are a ubiquitous part of modern life. These are activities involving low energy expenditure (1-1.5 metabolic equivalents)[1] such as sitting at work, watching TV and driving a car, and are distinct from a lack of moderate-to-vigorous physical activity.[2] Time spent being sedentary may be associated with increased risk of chronic illness and mortality independent of physical activity [3-5].

Population surveillance indicates that the prevalence of sitting and sedentary behaviour is high. The International Prevalence Study of physical activity, which surveyed self-reported sitting times in 20 countries, found that adults report sitting for five to six hours per day on average.[6] Other population studies, which objectively assessed sedentary time with accelerometers, found that adults are sedentary for approximately $57 \%$ of their waking time. $[7,8]$ However, current prevalence data on sitting and sedentary behaviours are limited to single data collection periods with inadequate contextual detail about sedentary behaviour and so little is known about changes over time in adult sitting and sedentary behaviour in defined populations.

Time use surveys have been conducted since the 1960s in many countries and provide a hitherto untapped resource for examining trends in sedentary behaviour [9]. Previous studies have linked metabolic equivalent (MET) values to activity codes used in time use surveys allowing researchers to study the population prevalence of different activities by intensity and domain [9-12]. Research has examined population levels of physical activity and active transport using time use data [13-15], but sedentary behaviour has received less attention. Time use diaries provide a valid and reliable measurement of nonoccupational sedentary behaviours [9].

In this paper, we examine trends in Australian adults' time use by activity domain and intensity with data from the Australian Time Use Surveys in 1992, 1997 and 2006. We focus particularly on sedentary time and changes in time spent in non-occupational sedentary behaviours and more specifically on sedentary behaviours during leisure time.

\section{Methods}

\section{Australian Bureau of Statistics Time Use Survey}

The Australian Bureau of Statistics (ABS) conducted cross-sectional Australian Time Use Surveys in 1992, 1997 and 2006 [16-18]. The ABS randomly selected private dwellings in Australia to participate in each survey. Trained ABS interviewers collected information from one adult member of each household about all persons aged at least 20 years old in the household via computer-assisted interviews. Each person was then given time use diaries to record all their activities over two specified consecutive days. The time use diary consisted of two 24-hour activity logs with 5-minute intervals. Participants recorded their main (primary) and any accompanying (secondary) activities in their own words in their time use diaries and their responses were later coded into standard activities by trained ABS coders. Surveys were conducted throughout the calendar year by quarter. Response rates for the 1992, 1997 and 2006 Time Use Surveys were 82.9 \%, 84.5 \% and $82.5 \%$, respectively. This study had ABS approval to access the 1992, 1997 and 2006 Australian Time Use Surveys via Confidentialised Unit Record Files.

Time use diaries with over 20 activity episodes recorded per day are considered to have acceptable data quality.[19,20] The average number of episodes recorded per diary day in the three Australian Time Use Surveys for day 1 and day 2 was, respectively, 31.8 and 30.2 in 1992, 29.1 and 27.5 in 1997, and 28.9 and 27.0 in 2006, indicating good data quality in all surveys.

\section{Data treatment}

We matched the ABS activity codes used in the 1992 and 1997 Time Use Surveys to those used in the 2006 survey so that codes would be consistent across the surveys. We then assigned to all primary activities an intensity classification based on the Compendium of Physical Activities [1] and the intensity coding system used in the American Time Use Survey.[10] The intensity classification comprised three categories defined by metabolic equivalents (MET; $1 \mathrm{MET}=4.184 \mathrm{~kJ}$ per kilogram of body weight per hour): sedentary activities $(<=1.5$ METs), light activities ( $>1.5$ to $<3 \mathrm{METs}$ ), moderateto-vigorous activities ( $>=3$ METs) and occupational activities. This method for estimating non-occupational sedentary, light and moderate-to-vigorous intensity activity has been previously validated and has shown good test-retest reliability (intraclass correlations 0.74, 0.46, and 0.73 , respectively) and validity when compared to accelerometers (Spearman correlations 0.57-0.59, 0.27-0.39, and 0.45-0.69, respectively) [9]. We could not code occupational activities for intensity because time at work was not broken down into specific occupational activities. We also recoded all activities into domains commonly used in physical activity research: occupational, household, leisure and transportation. Examples of sedentary household activities include clothes making, paperwork, budgeting and communications associated with domestic activities and childcare. Examples of leisure sedentary activities include attendance at movies and sports matches, games, handcraft, watching TV, and reading books. Transport modes were categorised as sedentary (car, bus, ferry, train), light (motorcycle), moderate-to-vigorous (walking, cycling) and unspecified [9]. All activities classified as moderate-to-vigorous are referred to as "moderate" activities in this paper. 
Overall, the matched activity coding scheme was consistent across the three surveys. Some coding differences in 1992 meant that we could not synchronise activities in that survey with those in the 1997 and 2006 surveys in some domains. The lack of "with/for whom" information in 1992 affected the coding of social and household activities and limited comparability of leisure and household domains with subsequent surveys. Time spent in the sleep domain in 1997 and 2006 encompassed sleeping, napping and sleeplessness; however napping and sleeplessness were not coded in 1992 and so time spent in the sleep domain in 1992 was not comparable with that measured in later surveys. Hence, we could only make limited comparisons for the 1992 time use survey with those from 1997 and 2006.

New communication categories were devised to standardise and delineate communication with and without a computer. In 1992, The ABS originally coded communication as separate activities (i.e., written, in person, by computer, by phone), whereas in 1997 and 2006 they coded communication as "communication" and then coded the technology involved as a separate variable (in person, fixed phone, mobile phone, written, sms, fax, internet, personal computer). We recoded all communication involving internet or personal computers as computing and further grouped them into subcategories: computing for occupation, computing for household, computing for leisure and computing for education. All other communication modes were then coded as non-computer communication (written, in person, by phone).

\section{Analyses}

We aggregated episode level data to the person level for analysis. Only people with two complete days of diary data were included: $\mathrm{n}=6420(91.0 \%)$ in $1992 ; \mathrm{n}=6703$ (92.3 \%) in 1997; $\mathrm{n}=6018$ (87.2 \%) in 2006. Data were weighted to the person-day to account for the probability of each person being selected by day type (week, weekend day) and then the distribution was adjusted based on population benchmarks for quarter of the year, age, sex, employment, and region of that survey year. The final weighted samples for each survey year were: $\mathrm{n}=5851$ (1992), $\mathrm{n}=6419$ (1997) and $\mathrm{n}=5505$ (2006).

We computed minutes spent over two days in activities by domain and intensity and domain-intensity combinations. Descriptive data are presented as mean and standard deviations over two complete diary days (2880 minutes). Changes in time spent in non-occupational sedentary activities across year of survey were analysed using multiple linear regressions adjusted for sex, age, education and employment status with 2006 as the reference year. The beta coefficient represents the average change per minute over two diary days in time spent in activities in 1992 or 1997 compared to 2006 (a negative coefficient indicates an increase in 2006).

\section{Results}

Table 1 presents the weighted participant characteristics for the Australian Time Use Surveys of 1992, 1997 and 2006. While there were differences in the distributions by education and employment status across the survey

Table 1 Weighted participant characteristics by year of Australian Time Use Surveys 1992, 1997, 2006 (column \%) $^{1}$

\begin{tabular}{|c|c|c|c|c|c|c|c|}
\hline & & \multicolumn{2}{|c|}{1992} & \multicolumn{2}{|c|}{1997} & \multicolumn{2}{|c|}{2006} \\
\hline & & $n$ & $\%$ & $\mathrm{n}$ & $\%$ & $\mathrm{n}$ & $\%$ \\
\hline All & & 5851 & 100 & 6419 & 100 & 5505 & 100 \\
\hline \multirow[t]{2}{*}{ Sex } & Male & 2906 & 49.7 & 3149 & 49.1 & 2678 & 48.7 \\
\hline & Female & 2945 & 50.3 & 3269 & 50.9 & 2826 & 51.3 \\
\hline \multirow[t]{6}{*}{ Age group } & $20-29$ & 659 & 11.3 & 665 & 10.4 & 495 & 9.0 \\
\hline & $30-39$ & 1386 & 23.7 & 1417 & 22.1 & 1030 & 18.7 \\
\hline & $40-49$ & 1299 & 22.2 & 1411 & 22.0 & 1133 & 20.6 \\
\hline & $50-59$ & 927 & 15.8 & 1171 & 18.2 & 1073 & 19.5 \\
\hline & $60-69$ & 714 & 12.2 & 834 & 13.0 & 846 & 15.4 \\
\hline & $70+$ & 866 & 14.8 & 920 & 14.3 & 927 & 16.8 \\
\hline \multirow[t]{3}{*}{ Education } & High school or less & 2970 & 50.8 & 3094 & 48.2 & 2666 & 48.4 \\
\hline & Diploma, certificate & 2185 & 37.3 & 2169 & 33.8 & 1625 & 29.5 \\
\hline & Bachelor degree or higher & 696 & 11.9 & 1156 & 18.0 & 1214 & 22.1 \\
\hline \multirow[t]{4}{*}{ Employment status } & Employed full-time & 2686 & 45.9 & 2928 & 45.6 & 2491 & 45.3 \\
\hline & Employed part-time & 804 & 13.8 & 979 & 15.2 & 1068 & 19.4 \\
\hline & Unemployed & 441 & 7.5 & 326 & 5.1 & 133 & 2.4 \\
\hline & Not in labour force & 1920 & 32.8 & 2185 & 34.0 & 1812 & 32.9 \\
\hline
\end{tabular}

${ }^{1}$ Weighted for probability of being sampled in the Australian population by day type (week, weekend) and for population age, sex, employment status, region for survey year distributions. 
years, these reflected genuine secular trends in the Australian adult population rather than artefacts of sampling [21-23].

Table 2 shows the minutes in primary activities by domain and intensity over two diary days for the Australian Time Use Surveys of 1992, 1997 and 2006. There was no change in time spent in the sleep or occupation domains. Total time spent in education showed some significant increases over time but the effect sizes were small ( $<7$ minutes).

We found no change in time spent in nonoccupational activities during waking time (i.e., transport, leisure, household and education domains) from 1997 to 2006. On average, respondents spent approximately $51 \%$ of their time in non-occupational activities of which $62 \%$ was sedentary. Relative to 2006, sedentary non- occupational activity time was significantly lower in 1997 and moderate non-occupational activity time was significantly higher in 1997, both by about 11 minutes over two days.

Total time spent in transportation in both 1992 and 1997 was not significantly different to that in 2006. However time spent in sedentary modes of transport (i.e. car, bus, train) was significantly lower in 1992 $(\mathrm{B}=-3.9$; 95\%CI: $-7.7,-0.1)$ and $1997(\mathrm{~B}=-6.7$; 95\%CI: $-10.4,-3.0)$ than in 2006, although again effect sizes were small. There was a small drop in time in active transport (i.e. walking and cycling) between 1992 and 2006 ( $\mathrm{B}=1.4$; 95 \% CI: 0.3, 2.6), while time in unspecified transport modes was significantly higher in 1992 $(\mathrm{B}=1.7$; 95\%CI: $0.2,3.3)$ and 1997 (B= 5.4; 95\%CI: 3.9, 6.9) than in 2006.

Table 2 Minutes spent in primary activities by domain and intensity over two diary days, Australian Time Use Surveys 1992, 1997 and $2006^{1}$

\begin{tabular}{|c|c|c|c|c|c|c|c|c|c|}
\hline \multirow[b]{2}{*}{ Domain } & \multirow[b]{2}{*}{ Intensity level } & \multicolumn{3}{|c|}{$1992(n=5851)$} & \multicolumn{3}{|c|}{$1997(n=6419)$} & \multicolumn{2}{|c|}{$\begin{array}{l}\text { Reference year } \\
2006(n=5505)\end{array}$} \\
\hline & & Mean (SD) & $\%$ time & B $(95 \% \mathrm{CI})^{2}$ & Mean (SD) & $\%$ time & B $(95 \% \mathrm{Cl})^{2}$ & Mean (SD) & $\%$ time \\
\hline Sleep $^{3}$ & Total & - & - & - & $1022.6(185.0)$ & 35.5 & $-0.02(-6.4,6.4)$ & $1018.4(180.8)$ & 35.4 \\
\hline Occupation & Total & $393.4(470.1)$ & 13.7 & $10.1(-2.5,22.8)$ & $381.5(456.8)$ & 13.2 & $-2.3(-14.6,10.0)$ & $391.4(456.1)$ & 13.6 \\
\hline \multirow[t]{5}{*}{ Transport } & Total & $149.3(110.7)$ & 5.2 & $-0.7(-4.8,3.5)$ & $148.4(120.9)$ & 5.2 & $-2.1(-6.1,2.0)$ & $149.2(111.9)$ & 5.2 \\
\hline & Sedentary & 119.9 (105.2) & 4.2 & $-3.9(-7.7,-0.10)$ & $118.0(107.0)$ & 4.1 & $-6.7(-10.4,-3.0)$ & $124.3(104.2)$ & 4.3 \\
\hline & Light & $0.7(10.2)$ & 0.0 & $0.10(-0.4,0.5)$ & $0.7(11.5)$ & 0.0 & $0.1(-0.3,0.6)$ & $0.5(12.3)$ & 0.0 \\
\hline & Moderate & $14.3(32.0)$ & 0.5 & $1.4(0.3,2.6)$ & $12.0(28.3)$ & 0.4 & $-0.9(-2.0,0.2)$ & $12.4(30.4)$ & 0.4 \\
\hline & Unspecified mode & $14.4(39.2)$ & 0.5 & $1.7(0.2,3.3)$ & $17.8(51.6)$ & 0.6 & $5.4(3.9,6.9)$ & $12.0(32.0)$ & 0.4 \\
\hline \multirow[t]{4}{*}{ Leisure $^{3}$} & Total & - & - & - & $580.7(311.9)$ & 20.2 & $23.2(13.0,33.4)$ & $559.1(314.1)$ & 19.4 \\
\hline & Sedentary & - & - & - & $509.1(288.0)$ & 17.7 & $5.1(-4.5,14.6)$ & $505.7(294.5)$ & 17.6 \\
\hline & Light & - & - & - & $31.1(81.5)$ & 1.1 & $12.8(10.1,15.4)$ & $18.7(65.5)$ & 0.6 \\
\hline & Moderate & - & - & - & 40.5 (95.4) & 1.4 & $5.3(1.7,9.0)$ & $34.8(77.8)$ & 1.2 \\
\hline \multirow[t]{4}{*}{ Household $^{3}$} & Total & - & - & - & 726.4 (361.5) & 25.2 & $-12.5(-23.3,-1.8)$ & 737.8 (367.4) & 25.6 \\
\hline & Sedentary & - & - & - & $247.1(150.8)$ & 8.6 & $-3.6(-8.5,1.3)$ & $251.7(154.6)$ & 8.7 \\
\hline & Light & - & - & - & $350.6(237.7)$ & 12.2 & $-14.9(-22.2,-7.7)$ & $362.4(238.8)$ & 12.6 \\
\hline & Moderate & - & - & - & $128.6(154.0)$ & 4.5 & $6.0(0.8,11.3)$ & $123.7(153.4)$ & 4.3 \\
\hline \multirow[t]{4}{*}{ Education } & Total & $23.0(123.8)$ & 0.8 & $-3.4(-7.7,1.0)$ & $20.4(116.1)$ & 0.7 & $-6.3(-10.5,-2.1)$ & $24.0(123.4)$ & 0.8 \\
\hline & Sedentary & $22.9(123.5)$ & 0.8 & $-3.2(-7.5,1.1)$ & $20.1(114.9)$ & 0.7 & $-6.3(-10.5,-2.2)$ & $23.8(122.8)$ & 0.8 \\
\hline & Light & $0.1(6.3)$ & 0.0 & $-0.1(-0.4,0.1)$ & $0.4(5.9)$ & 0.0 & $0.1(-0.1,0.3)$ & $0.3(4.4)$ & 0.0 \\
\hline & Moderate $^{4}$ & - & - & - & - & - & - & - & \\
\hline \multirow{4}{*}{$\begin{array}{l}\text { Non-occupational } \\
\text { waking time }\end{array}$} & Total $^{5}$ & - & - & - & $1475.9(439.3)$ & 51.2 & $3.5(-8.5,15.6)$ & $1470.2(435.4)$ & 51.0 \\
\hline & Sedentary & - & - & - & 894.3 (315.9) & 31.1 & $-11.2(-21.5,-0.9)$ & 905.5 (320.7) & 31.4 \\
\hline & Light & - & - & - & 382.7 (251.9) & 13.3 & $-1.5(-8.8,5.8)$ & $381.7(247.3)$ & 13.3 \\
\hline & Moderate & - & - & - & 181.1 (179.6) & 6.3 & $10.9(4.8,17.0)$ & 170.9 (171.8) & 5.9 \\
\hline
\end{tabular}

${ }^{1}$ Weighted for probability of being sampled in the Australian population by day type (week, weekend) and for population age, sex, employment status, region for survey year distributions.

${ }^{2}$ Reference year is 2006; models additionally adjusted for age, sex, education level and employment status.

${ }^{3}$ Data not presented for 1992 because changes to coding in 1997 and 2006 meant that time spent in activities in sleep, leisure and household domains were not comparable.

${ }^{4}$ There was no time in moderate education activities recorded.

${ }^{5}$ Total non-occupational waking time includes time in transport, leisure, household and education domains. 
Relative to 2006, total leisure time was significantly higher in 1997 ( $B=23.2 ; 95 \% C I$ : 13.0, 33.4). While there was no change between 1997 and 2006 in sedentary leisure time, time in light and moderate leisure activities was significantly higher in 1997 than in 2006 ( $\mathrm{B}=12.8 ; 95 \% \mathrm{CI}: 10.1,15.4$; and $\mathrm{B}=5.3$; 95\%CI: 1.7 , 9.0, respectively).

Total time spent in household activities was significantly lower in 1997 than in 2006 ( $B=-12.5$; 95\%CI: -23.3, -1.8). There was no difference in sedentary household activity time in 2006 versus 1997. Compared to 2006, time in light household activities was significantly lower in 1997 ( $\mathrm{B}=-14.9$; 95\% CI: -22.2,-7.7) and time in moderate household activities was significantly higher in 1997 (B = 6.0; 95\%CI: 0.8, 11.3).

Stratified analyses by sex (data not shown) found that there was a significant increase in total nonoccupational sedentary time from 1997 to 2006 in men $(1997$ mean $=890.1 \mathrm{~min} / 2 \mathrm{~d}$ versus 2006 mean $=910.7$ $\mathrm{min} / 2 \mathrm{~d} ; \mathrm{B}=-16.6 ; 95 \% \mathrm{CI}:-31.9,-1.3)$, but not in women $(1997$ mean $=898.4 \mathrm{~min} / 2 \mathrm{~d}$ versus 2006 mean $=900.6$ $\mathrm{min} / 2 \mathrm{~d} ; \mathrm{B}=-5.0$; 95\%CI: $-18.8,8.8)$. Compared to 2006, time in sedentary leisure activities was higher in 1997 in women $(1997$ mean $=498.4 \mathrm{~min} / 2 \mathrm{~d}$ versus 2006 mean $=$ $483.2 \mathrm{~min} / 2 \mathrm{~d} ; \mathrm{B}=17.0 ; 95 \% \mathrm{CI}$ : 4.7, 29.2), while men showed no significant change $(1997$ mean $=520.3 \mathrm{~min} / 2 \mathrm{~d}$ versus 2006 mean $=529.5 \mathrm{~min} / 2 \mathrm{~d} ; \mathrm{B}=-5.7 ; 95 \% \mathrm{CI}:-19.8$, 8.5) Moderate leisure time decreased from 1997 to 2006 in men only (1997 mean $=51.5 \mathrm{~min} / 2 \mathrm{~d}$ versus 2006 mean $=42.5 \mathrm{~min} / 2 \mathrm{~d} ; \mathrm{B}=8.9 ; 95 \% \mathrm{CI}$ : 3.4, 14.3). From 1997 to 2006, women's time spent doing household activities significantly increased $(1997$ mean $=871.7 \mathrm{~min} /$
$2 \mathrm{~d}$ versus 2006 mean $=878.1 \mathrm{~min} / 2 \mathrm{~d} ; \mathrm{B}=-18.0 ; 95 \%$ CI: -33.5, -2.6); time spent in light household activities increased $(1997$ mean $=469.7 \mathrm{~min} / 2 \mathrm{~d}$ versus 2006 mean $=476.8 \mathrm{~min} / 2 \mathrm{~d} ; \mathrm{B}=-17.4 ; 95 \% \mathrm{CI}$ : $-28.6,-6.3)$ and time in moderate household activities decreased (1997 mean $=137.0 \mathrm{~min} / 2 \mathrm{~d}$ versus 2006 mean $=130.7 \mathrm{~min} / 2 \mathrm{~d}$; $\mathrm{B}=6.6$; 95\%CI: 0.1, 13.1). Men reported significantly increased time in light household activities from 1997 to 2006 (1997 mean $=227.0 \mathrm{~min} / 2 \mathrm{~d}$ versus 2006 mean $=$ $241.6 \mathrm{~min} / 2 \mathrm{~d} ; \mathrm{B}=-12.4 ; 95 \% \mathrm{CI}$ : $-20.1,-4.7)$ while there was no change in their sedentary, moderate or total household time.

Total time in all leisure-time sedentary behaviours constituted $57 \%$ and $56 \%$ of total sedentary waking hours in 1997 and 2006, respectively. Table 3 presents a breakdown of the minutes spent in leisure-time sedentary activities by primary activity. TV-viewing time did not differ between 1997 and 2006.Time spent using the computer in leisure time was almost half an hour lower in 1997 than in 2006 ( $B=-26.7$; 95\%CI: -29.5, -23.8). At the same time, there were small significant declines from 1997 to 2006 in other leisure-time sedentary behaviours: reading, relaxing and resting, listening to music, hobbies and crafts and non-computer forms of communication.

Table 4 focuses on time spent in screen-based activities and showed significantly lower total screen time in 1992 $(\mathrm{B}=-62.0 ; 95 \% \mathrm{CI}:-69.4,-54.6)$ and $1997(\mathrm{~B}=-24.2 ; 95 \%$ CI: $-31.3,-17.0)$ relative to 2006 . Furthermore, leisuretime computing showed a marked change over the three surveys with significantly less computer use for leisure in $1992(\mathrm{~B}=-35.3 ;$ 95\%CI: $-37.7,-32.8)$ and in 1997 (B $=-26.4 ; 95 \% \mathrm{CI}:-28.8,-24.0)$ compared with 2006.

Table 3 Changes in minutes spent in leisure-time sedentary behaviour (primary activities) over two diary days, Australian Time Use Surveys 1997 and $2006^{1}$

\begin{tabular}{|c|c|c|c|c|c|}
\hline \multirow[b]{2}{*}{$\begin{array}{l}\text { Leisure-time sedentary } \\
\text { behaviour }\end{array}$} & \multicolumn{3}{|c|}{$1997(n=6419)$} & \multicolumn{2}{|c|}{ Reference year $2006(n=5505)$} \\
\hline & Mean (SD) & $\%$ of domain & B $95 \% ~ C l)^{2}$ & Mean (SD) & $\%$ of 2 domain \\
\hline Watching TV & $236.9(203.1)$ & 46.5 & $3.4(-3.4,10.2)$ & $231.7(195.9)$ & 45.8 \\
\hline $\begin{array}{l}\text { Socialising, } \\
\text { community interaction }\end{array}$ & $71.3(113.0)$ & 14.0 & $-2.4(-6.5,1.8)$ & $73.3(115.8)$ & 14.5 \\
\hline Reading & $53.5(88.7)$ & 10.5 & $6.3(3.3,9.4)$ & $50.5(91.1)$ & 10.0 \\
\hline Relaxing, resting & $27.8(70.8)$ & 5.5 & $3.2(0.8,5.6)$ & $25.9(64.5)$ & 5.1 \\
\hline Listening to music & $15.1(49.9)$ & 3.0 & $6.5(4.9,8.1)$ & $9.3(38.6)$ & 1.8 \\
\hline Hobbies, arts, crafts & $12.1(49.9)$ & 2.4 & $2.5(0.8,4.3)$ & $10.0(44.3)$ & 2.0 \\
\hline Using computer & $11.8(57.2)$ & 2.3 & $-26.7(-29.5,-23.8)$ & $37.5(99.5)$ & 7.4 \\
\hline $\begin{array}{l}\text { Communication by } \\
\text { phone, written, } \\
\text { in person }\end{array}$ & $73.4(93.9)$ & 14.4 & $10.1(6.9,13.3)$ & $62.7(84.7)$ & 12.4 \\
\hline Other & 7.4 (37.4) & 1.5 & $2.1(1.0,3.3)$ & $4.8(24.8)$ & 1.0 \\
\hline
\end{tabular}

${ }^{1}$ Weighted for probability of being sampled in the Australian population by day type (week, weekend) and for population age, sex, employment status, region for survey year distributions.

${ }^{2}$ Reference year is 2006; models additionally adjusted for age, sex, education level and employment status. 
Table 4 Changes in minutes spent in screen-based primary activities over two diary days, Australian Time Use Surveys 1992,1997 and $2006^{1}$

\begin{tabular}{|c|c|c|c|c|c|c|}
\hline \multirow[b]{2}{*}{$\begin{array}{l}\text { Screen time } \\
\text { domain }\end{array}$} & & \multicolumn{2}{|c|}{$1992(n=5851)$} & \multicolumn{2}{|c|}{$1997(n=6419)$} & \multirow{2}{*}{$\begin{array}{l}\text { Reference yea } \\
2006(n=5505) \\
\text { Mean (SD) }\end{array}$} \\
\hline & & Mean (SD) & B $(95 \% \mathrm{Cl})^{2}$ & Mean (SD) & B $(95 \% \mathrm{Cl})^{2}$ & \\
\hline Total & & 216.7 (203.5) & $-62.0(-69.4,-54.6)$ & $250.4(211.6)$ & $-24.2(-31.3,-17.0)$ & $271.9(220.8)$ \\
\hline \multirow[t]{2}{*}{ Leisure } & $\begin{array}{l}\text { Watching TV, } \\
\text { DVD, videos }\end{array}$ & $214.0(202.0)$ & $-24.2(-31.2,-17.2)$ & $236.9(203.1)$ & $3.2(-3.6,10.0)$ & $231.7(195.9)$ \\
\hline & Computing & $2.6(22.8)$ & $-35.3(-37.7,-32.8)$ & $11.8(57.2)$ & $-26.4(-28.8,-24.0)$ & 37.5 (99.5) \\
\hline Household & Computing & $0.0(1.0)$ & $-1.7(-2.1,-1.3)$ & $0.8(11.0)$ & $-0.9(-1.3,-0.5)$ & $1.8(14.9)$ \\
\hline Education & Computing & $0.1(3.5)$ & $-0.9(-1.3,-0.4)$ & 0.9 (15.3) & $-0.1(-0.6,0.3)$ & $1.0(14.3)$ \\
\hline
\end{tabular}

${ }^{1}$ Weighted for probability of being sampled in the Australian population by day type (week, weekend) and for population age, sex, employment status, region for survey year distributions.

${ }^{2}$ Reference year is 2006; models additionally adjusted for age, sex, education level and employment status.

\section{Discussion}

This study examined trends in Australian adults' time use by activity domain and intensity using data from the Australian Time Use Surveys in 1992, 1997 and 2006 with particular attention given to changes in time engaged in non-occupational sedentary behaviour. To our knowledge, this is the first population study to report on temporal changes in adult non-occupational sedentary time. While previous studies have described trends in TV-viewing time, car use or walking $[12,24]$ we present detailed prevalence data on a range of different sedentary behaviours in Australian adults over a 9- to 14-year timeframe.

Our findings suggest that non-occupational sedentary waking time has increased slightly in recent years among Australian adults. This increase was primarily due to small increases in sedentary transport and education time, while sedentary household and leisure time remained stable. We also found that the distribution of different leisure-time sedentary activities changed, while total sedentary leisure time remained stable. For example, leisure-time computer use showed a significant increase from 1997 to 2006, but other leisure-time sedentary behaviours (e.g., reading, listening to music, hobbies and crafts) showed small reductions concurrently. Total screen time increased over the 14 years between 1992 and 2006, again mostly due to growth in computer use.

Many of the studies on the adverse effects of sedentary time on health are based on watching television [25-28]. A recent meta-analysis showed that prolonged TV-viewing is associated with higher risk of type 2 diabetes, fatal and non-fatal cardiovascular disease and all-cause mortality. [29] In the present study, there was only a modest increase in watching television between 1992 and 2006, but the increase in total screen time was more substantial and might be of public health significance. Our results also showed that $90 \%$ of leisure time in 2006 was spent sedentary and over half (53\%) of that consisted of screen time. It is likely that these upward trends in screen time will continue given the increasing reliance of modern life on computer technology. Therefore, studies of the associations between these types of sedentary behaviours and health outcomes are warranted, especially as much of the focus to date has been on TV-viewing time. Furthermore, these data suggest that reducing $\mathrm{TV}$-viewing and other screen time may be good targets for public health interventions. Advances in technology may complicate future research with less distinction between types of sedentary behaviours as they become increasingly screen-based with the development of smart phones and tablet devices.

We found that time using sedentary modes of transport rose slightly between 1992 and 2006, while time in moderate intensity transport modes showed a small concurrent decline. There were also small but significant increases in time spent in unspecified modes of transport for which activity intensity could not be determined and makes the drawing of conclusions more difficult. Findings from Australian and American studies suggest that the prevalence of car use is high and has increased, while active transport, with relatively low prevalence, has changed little [24,30,31]. Built environment and transport policies and active transport promotion can influence active travel [32,33]. It is possible that use of active transport modes may increase in the future given growing interest and calls to action in Australia about implementing new transport and built environment infrastructure and policies to encourage more active transport [34-37]. Further monitoring through analyses similar to those presented here could track such changes.

We found that total time in household activities increased in women but not in men from 1997 to 2006. Women's time in sedentary household tasks did not change over this period, but time doing light household activities increased while that for moderate household activities decreased. It is possible that the decline in moderate household activities is due to increased consumption of labour-saving goods and services over this period [38]. 
It is not clear whether the changes in sedentary time found in this study could affect health outcomes as research is yet to establish thresholds for sitting time which compromise health [39]. There are currently no official adult guidelines for sedentary behaviour, although the Australian National Heart Foundation recommends limiting screen-based activities to less than two hours per day [40].

\section{Strengths and limitations}

The key strength of this study is the use of data from three cross-sectional population-based time use surveys. The response rates from each survey were relatively high (all $>80 \%$ ) and data quality was also high (average number of episodes recorded per diary day ranged from 27 to 31). $[19,20]$ A further advantage is that time use surveys are not health-focused. Participants report all of their time use over the diary measurement period and they are not explicitly asked to focus on their physical activity or sedentary behaviour. So, potential social desirability related to physical activity and sedentary behaviour when completing time use surveys is likely to be low,[13] resulting in less reporting bias than in other self-report measures of physical activity and sedentary behaviour, which was illustrated in a previous comparison of time use diaries against accelerometers [9].

This study was limited by the lack of detail about occupational activities reported in the Time Use Surveys. We found that there were no changes in time spent in the occupational domain from 1992 to 2006, but could not determine the intensity level of occupational activities and the possible changes in sedentary, light and moderate occupational activities over the survey years. It is possible that time spent in sedentary and light occupational activities have risen while that for moderate occupational activities declined, in light of population trends in the US and England [41-43]. Thus, total sedentary time during waking hours in Australian adults would probably be higher if potential occupational sedentary time could have been factored in.

Changes in activity coding after 1992 limited the analyses of trends in the sleep, household and leisure domains to comparing changes between 1997 and 2006 Time Use Surveys only. We were not able to compare time spent in leisure and household activities in 1992 with that in 1997 and 2006 due to the lack of "with/for whom" information in 1992 which affected the coding of social and household activities. Nonetheless, we were able to standardise codes for computer use in all three surveys which allowed for the analysis of trends in screen time across a 14-year period. Other studies have reported issues with changes in coding systems in time use surveys over several cycles and researchers have similarly harmonised data to examine changes in time spent in certain behaviours over time $[11,12]$.

\section{Conclusions}

Australian adults' time engaged in non-occupational sedentary activities has increased slightly from 1997 to 2006. This appears to be the result of small increases in sedentary transport and education time while sedentary household and leisure time were stable over this time period. However, $90 \%$ of leisure time is spent sedentary and the composition of sedentary leisure time changed between 1992 and 2006, with the proportion of time devoted to TV-watching and leisure-time computer use increasing over 14 years. As the literature has focused on the detrimental effects of TV-viewing and health, these increases in screen time have serious public health implications. With almost all leisure-time spent sedentary, leisure-time seems a suitable target for public health interventions aimed at reducing sedentary behaviour as the potential gains would be substantial. Future research should focus on the detrimental effects of different types of sedentary behaviour in order to determine if certain sedentary behaviours such as TV-viewing are more harmful than others.

This study makes a unique contribution in that we report trends in a range of different sedentary behaviours by domain in a population-representative sample of Australian adults. It also demonstrates the utility of time use surveys for studying trends in non-occupational sedentary behaviours when time trend data on population prevalence of sedentary behaviours are limited.

\section{Competing interests}

The authors declare that they have no competing interests.

\section{Acknowledgements}

This study was supported by funding from the Australian National Health and Medical Research Council Program Grant \#301200. JYC was supported by a University of Sydney Postgraduate Award. DM is a Post Doctoral Research Fellow supported by Australian National Health and Medical Research Council project \#571150.

\section{Author details}

${ }^{1}$ Prevention Research Collaboration, Sydney School of Public Health, University of Sydney, Sydney, Australia. ${ }^{2}$ School of Biomedical and Health Sciences, University of Western Sydney, Sydney, Australia.

\section{Authors' contributions}

JYC and HPVDP conceptualised the study and research questions. JYC obtained permission for data access, analysed and interpreted the data, and drafted the manuscript. HPVDP, DM and AG contributed to data analysis and provided statistical advice. HPVDP, CR, AEB, DM, AG contributed to interpreting the data. All authors critically revised the manuscript for intellectual content, read and approved the final manuscript.

Received: 20 January 2012 Accepted: 19 June 2012 Published: 19 June 2012

\section{References}

1. Ainsworth BE, Haskell WL, Whitt MC, Irwin ML, Swartz AM, Strath SJ, O'Brien WL, Bassett DR Jr, Schmitz KH, Emplaincourt PO, et al: Compendium of 
physical activities: an update of activity codes and MET intensities. Med Sci Sports Exerc 2000, 32:S498-S504.

2. Pate RR, O'Neill JR, Lobelo F: The Evolving Definition of "Sedentary". Exerc Sport Sci Rev 2008, 36:173-178.

3. van Uffelen JGZ, Wong J, Chau JY, van der Ploeg HP, Riphagen I, Gilson N, Burton NW, Healy GN, Thorp AA, Clark BK, et al: Occupational sitting and health risks: A systematic review. Am J Prev Med 2010, 39:379-388.

4. Proper Kl, Singh AS, van Mechelen W, Chinapaw MJM: Sedentary Behaviors and Health Outcomes Among Adults: A Systematic Review of Prospective Studies. Am J Prev Med 2011, 40:174-182.

5. van der Ploeg HP, Chey T, Korda R, Banks E, Bauman AE: Sitting Time and All-Cause Mortality Risk in 202,481 Australian Adults. Arch Intern Med 2012, 172:494-500

6. Bauman A, Ainsworth BE, Sallis JF, Hagestromer M, Craig CL, Bull FC, Pratt M, Venugopal K, Chau J, Sjostrom M: IPS Group: The descriptive epidemiology of sitting - a 20 country comparison using the International Physical Activity Questionnaire (IPAQ). Am J Prev Med 2011, 41:228-235.

7. Healy GN, Dunstan DW, Salmon J, Cerin E, Shaw JE, Zimmet PZ, Owen N Objectively Measured Light-Intensity Physical Activity Is Independently Associated With 2-h Plasma Glucose. Diabetes Care 2007, 30:1384-1389.

8. Healy GN, Matthews CE, Dunstan DW, Winkler EAH, Owen N: Sedentary time and cardio-metabolic biomarkers in US adults: NHANES 2003-06. Eur Heart J 2011, 32:590-597.

9. van der Ploeg HP, Merom D, Chau JY, Bittman M, Trost SG, Bauman AE: Advances in population surveillance for physical activity and sedentary behavior: reliability and validity of time use surveys. Am J Epidemiol 2010, 172:1199-1206.

10. Tudor-Locke C, Washington TL, Ainsworth BE, Troiano RP: Linking the American Time Use Survey (ATUS) and the Compendium of Physical Activities: methods and rationale. J Phys Act Health 2009, 6:347-353.

11. Spinney JEL, Millward H, Scott DM: Measuring active living in Canada: A time-use perspective. Soc Sci Res 2011, 40:685-694.

12. Tudor-locke C, van der Ploeg HP, Bowles HR, Bittman M, Fisher K, Merom D, Gershuny J, Bauman A, Egerton M: Walking behaviours from the 19652003 American Heritage Time Use Study ( AHTUS ). IJBNPA 2007, 4:45.

13. Tudor-Locke C, Bittman M, Merom D, Bauman A: Patterns of walking for transport and exercise: a novel application of time use data. IJBNPA 2005, 2:5.

14. Adams J: Prevalence and socio-demographic correlates of "active transport" in the UK: analysis of the UK time use survey 2005. Prev Med 2010, 50:199-203.

15. Dunton GF, Berrigan D, Ballard-Barbash R, Graubard B, Atienza AA: Joint associations of physical activity and sedentary behaviors with body mass index: results from a time use survey of US adults. Int J Obes 2009 33:1427-1436.

16. Australian Bureau of Statistics: Time Use Survey, Australia, 1992, User's guide (Catalogue No. 4150.0). Canberra: Commonwealth of Australia; 1993.

17. Australian Bureau of Statistics: Time Use Survey, Australia, Users' guide 1997 (Catalogue No. 4150.0). Canberra: Commonwealth of Australia; 1998.

18. Australian Bureau of Statistics: Time Use Survey, User guide, 2006 (Catalogue No. 4150.0). Canberra: Commonwealth of Australia; 2008.

19. Juster $\mathrm{FT}$ : The validity and quality of time use estimates obtained from recall diaries. In In Time, Goods, and Well-Being. Edited by Juster FT, Stafford FP. University of Michigan: Ann Arbo; 1985:63-91.

20. Robinson JP: The validity and reliability of diaries versus alternative time use measures. In In Time, Goods, and Well-Being. Edited by Juster FT, Stafford FP. University of Michigan: Ann Arbor; 1985:33-62.

21. Australian Bureau of Statistics, Australian Social Trends September 2011 (Catalogue No. 4102.0). Canberra: Commonwealth of Australia; 2011

22. Australian Bureau of Statistics, Australian Social Trends December 2011 (Catalogue No. 4102.0). Canberra: Commonwealth of Australia; 2011.

23. Australian Bureau of Statistics, Education and Work, Australia, May 2011 (Catalogue No. 6227.0). Canberra: Commonwealth of Australia; 2011.

24. Brownson RC, Boehmer TK, Luke DA: Declining rates of physical activity in the United States: what are the contributors? Annu Rev Public Health 2005, 26:421-443.

25. Thorp AA, Healy GN, Owen N, Salmon J, Ball K, Shaw JE, Zimmet PZ, Dunstan DW: Deleterious associations of sitting time and television viewing time with cardiometabolic risk biomarkers: Australian Diabetes,
Obesity and Lifestyle (AusDiab) study 2004-2005. Diabetes Care 2010, 33:327-334.

26. Wijndaele K, Brage S, Besson H, Khaw KT, Sharp SJ, Luben R, Wareham NJ, Ekelund U: Television viewing time independently predicts all-cause and cardiovascular mortality: the EPIC Norfolk study. Int J Epidemiol 2011, 40:150-159.

27. Dunstan DW, Barr EL, Healy GN, Salmon J, Shaw JE, Balkau B, Magliano DJ, Cameron AJ, Zimmet PZ, Owen N: Television viewing time and mortality: the Australian Diabetes, Obesity and Lifestyle Study (AusDiab). Circulation 2010, 121:384-391.

28. Hu FB, Li TY, Colditz GA, Willett WC, Manson JE: Television Watching and Other Sedentary Behaviors in Relation to Risk of Obesity and Type 2 Diabetes Mellitus in Women. JAMA 2003, 289:1785-1791.

29. Grøntved A, Hu FB: Television Viewing and Risk of Type 2 Diabetes, Cardiovascular Disease, and All-Cause Mortality. JAMA 2011, 305:2448-2455.

30. Merom D, van der Ploeg HP, Corpuz G, Bauman AE: Public health perspectives on household travel surveys active travel between 1997 and 2007. Am J Prev Med 2010, 39:113-121.

31. Pucher J, Buehler R, Merom D, Bauman A: Walking and cycling in the United States, 2001-2009: evidence from the national household travel surveys. Am J Public Health 2011, 101:S310-S317.

32. Pucher J, Dill J, Handy S: Infrastructure, programs, and policies to increase bicycling: An international review. Prev Med 2010, 50:S106-S125.

33. Ewing R, Cervero R: Travel and the Built Environment. J Am Plann Assoc 2010, 76:265-294.

34. City of Sydney: Sustainable Sydney 2030. Sydney, Australia: Community Strategic Plan (2011); 2011.

35. Wiggins D: Addressing Active Living through Councils' Integrated Planning and Reporting Framework. Sydney, Australia: Premier's Council for Active Living New South Wales; 2010.

36. Environment and Sustainable Development Directorate: Transport for Canberra. Transport for a sustainable city. Australian Capital Territory, Canberra: Transport for a sustainable city 2011-2031; 2011.

37. Rissel C: Prevention Research Collaboration Position Statement on Cycling in New South Wales.: ; 2011 [http://sydney.edu.au/medicine/public-health/ prevention-research/pdf/PP_cycling_Oct2011.pdf].

38. Australian Bureau of Statistics, Australian Social Trends 2007 (Catalogue No. 4102.0). Canberra: Commonwealth of Australia; 2007.

39. Owen N, Healy GN, Matthews CE, Dunstan DW: Too much sitting: the population health science of sedentary behavior. Exerc Sport Sci Rev 2010, 38:105-113.

40. National Heart Foundation of Australia: Sitting less for adults.: ; 2008 [http:// www.heartfoundation.org.au/SiteCollectionDocuments/ HW_PA_SittingLess_Adults_INFC_FINAL.pdf].

41. Church TS, Thomas DM, Tudor-Locke C, Katzmarzyk PT, Earnest CP, Rodarte RQ, Martin CK, Blair SN, Bouchard C: Trends over 5 Decades in U.S. Occupation-Related Physical Activity and Their Associations with Obesity. PloS One 2011, 6:e19657.

42. Stamatakis E, Ekelund U, Wareham NJ: Temporal trends in physical activity in England: the Health Survey for England 1991 to 2004. Prev Med 2007, 45:416-423.

43. Borodulin $\mathrm{K}$, Laatikainen $\mathrm{T}$, Juolevi A, Jousilahti P: Thirty-year trends of physical activity in relation to age, calendar time and birth cohort in Finnish adults. Eur J Public Health 2008, 18:339-344.

doi:10.1186/1479-5868-9-76

Cite this article as: Chau et al:: Temporal trends in non-occupational sedentary behaviours from Australian Time Use Surveys 1992, 1997 and 2006. International Journal of Behavioral Nutrition and Physical Activity 2012 9:76. 